\title{
Magnetic resonance imaging of RRx-001 pharmacodynamics in preclinical tumors
}

\author{
Natarajan Raghunand ${ }^{1}$, Jan Scicinski², Gerald P. Guntle ${ }^{3}$, Bhumasamudram \\ Jagadish ${ }^{4}$, Eugene A. Mash ${ }^{4}$, Elizabeth Bruckheimer ${ }^{5}$, Bryan Oronsky ${ }^{2}$ and Ronald \\ L. Korn ${ }^{5}$ \\ ${ }^{1}$ Moffitt Cancer Center, Tampa, Florida, USA \\ ${ }^{2}$ EpicentRx, Inc., San Diego, California, USA \\ ${ }^{3}$ Arizona Cancer Center, The University of Arizona, Tucson, Arizona, USA \\ ${ }^{4}$ Department of Chemistry and Biochemistry, The University of Arizona, Tucson, Arizona, USA \\ ${ }^{5}$ Imaging Endpoints LLC, Scottsdale, Arizona, USA \\ Correspondence to: Natarajan Raghunand, email: Natarajan.Raghunand@moffitt.org
}

Keywords: $R R x-001$, gadolinium, MRI, redox, BOLD

Received: August 15, $2016 \quad$ Accepted: May 22, $2017 \quad$ Published: June 12, 2017

Copyright: Raghunand et al. This is an open-access article distributed under the terms of the Creative Commons Attribution License 3.0 (CC BY 3.0), which permits unrestricted use, distribution, and reproduction in any medium, provided the original author and source are credited.

\section{ABSTRACT}

RRX-001 is an anticancer agent that subjects cancer cells to reactive oxygen/ nitrogen species (ROS/RNS) and acts as an epigenetic modifier. We have used a thiol-bearing MRI contrast agent, Gd-LC7-SH, to investigate the pharmacodynamics of RRx-001 in CHP-100 Ewing's Sarcoma, HT-29 colorectal carcinoma, and PANC-1 pancreatic carcinoma xenografts in SCID mice. Binding of Gd-LC7-SH to the Cys ${ }^{34}$ residue on plasma albumin prolongs retention in the tumor microenvironment and increases tumor enhancement on MRI. Mice were imaged by MRI and in vivo T1 maps acquired $50 \mathrm{~min}\left(\mathrm{T1}_{50 \mathrm{~min}}\right.$ ) after injection of $0.05 \mathrm{mmol} / \mathrm{kg} \mathrm{Gd}-\mathrm{LC7}-\mathrm{SH}$ (i.v.) at baseline and 1, 24, and $72 \mathrm{~h}$ post-treatment with $10 \mathrm{mg} / \mathrm{kg} \mathrm{RRx-001}$ (i.v.). Consistent with an indirect thiol-modifying activity of RRx-001, tumor $\mathrm{T1}_{50 \mathrm{~min}}$ at $1 \mathrm{~h}$ post-drug was significantly longer than pre-drug tumor $\mathrm{T1}_{50 \mathrm{~min}}$ in all three tumor models, with the $\mathrm{T1}_{50 \mathrm{~min}}$ remaining significantly longer than baseline through $\mathbf{7 2} \mathrm{h}$ post-drug in the HT-29 and PANC-1 tumors. The $\mathrm{T1}_{50 \text { min }}$ of CHP-100 tumors recovered to baseline by $24 \mathrm{~h}$ post-drug, suggesting a robust anti-oxidant response to the RRX-001 challenge that was presaged by a marked increase in perfusion at $1 \mathrm{~h}$ post-drug measured by DCE-MRI. MRI enhanced with Gd-LC7-SH provides a mechanistically rational biomarker of RRX-001 pharmacodynamics.

\section{INTRODUCTION}

RRx-001 is a member of the novel dinitroazetidinecontaining class of anticancer agents that perturbs the thiol redox potential of the cancer cell, subjecting it to damaging ROS/RNS [1] and acting as an epigenetic modifier $[2,3]$. With the successful completion of a first-in-human Phase 1 study [4], RRx-001 is currently being investigated in a number of Phase 2 clinical trials as an epigenetic primer to resensitize or "episensitize" patients to previously effective but now refractory therapies [5-10].
Pre-clinical studies have shown that RRx-001 (Figure 1A) selectively, rapidly, and irreversibly binds glutathione and a specific thiol on hemoglobin, resulting in a hypoxia-mediated, NO-releasing pro-oxidant effect in red blood cells that is transferred to tumors while sparing normal tissue [11-14]. Increases in intratumoral oxidative stress mediated by RRx- 001 have previously been measured in vitro with the fluorescent probe $2^{\prime}, 7^{\prime}$-dichlorofluorescein diacetate, and by studying the activation of the Nrf2-ARE antioxidant signaling pathways in tumor cells, specifically the nuclear translocation of 
$\mathrm{Nrf} 2$ and the expression of its downstream enzymes HO-1 and NQO1 by RRx-001 [12]. In addition, Nrf2ARE antioxidant signaling pathway activation was demonstrated in vivo by molecular imaging of tumor cells co-expressing pARE-Firefly luciferase and pCMV-Renilla luciferase-mRFP [13]. Treatment of $\mathrm{C} 3 \mathrm{H}$ mice bearing SCC VII tumors with RRx-001 alone, or in combination with radiation, produced significant dose- and timedependent increases in tumor perfusion and blood volume measured by microbubble-enhanced ultrasound imaging. The growth delay in these tumors produced by RRx001 treatment could be abrogated by co-administration of N-acetylcysteine [12]. Pre-clinical and clinical data indicate that RRx-001 metabolism leads to the depletion of reduced glutathione and generation of nitric oxide. Downstream sequelae of $\mathrm{RRx}-001$ reactivity include the oxidative modification of catalytic cysteine thiol groups and inactivation of crucial enzymes in the tumor microenvironment. Studying the tumor redox properties of RRx-001 will provide insight into the selection of biomarkers to identify patient populations that may benefit from the drug and to identify modalities that will enable pharmacodynamic monitoring of response in the clinic [15].

In this study we have interrogated the glutathioneand cysteine-depleting effects of RRx-001 using MRI enhanced with Gd-LC7-SH (Figure 1B), a chelate of gadolinium that exhibits increased longitudinal MRI relaxivity ( $\mathrm{r} 1$ relaxivity) upon binding with human serum albumin (HSA). The binding of Gd-LC7-SH to HSA is inhibited by homocysteine in a manner consistent with single site binding, and 2D NMR spectroscopy of the binding of a congener molecule Gd-LC6-SH $(n=6$ in Figure 1B) reveals that site to be the conserved $\mathrm{Cys}^{34}$ residue of HSA [16]. Albumin is known to combine with cysteine and homocysteine in plasma to form the respective mixed disulfides at its $\mathrm{Cys}^{34}$ residue. In a careful study of the binding of homocysteine to albumin, Jacobsen and colleagues provide evidence that when reduced homocysteine enters circulation, it attacks albumin-Cys ${ }^{34}$ -
S-S-Cys to first form albumin-Cys ${ }^{34}$ thiolate anion, which then reacts with homocysteine-cysteine mixed disulfide to form albumin-bound homocysteine [17]. Based on their findings, in Figure 2A we propose mechanisms by which i.v. administered Gd-LC7-SH may bind to plasma albumin and subsequently be retained in the tumor interstitium to produce prolonged MRI image enhancement. Albumin$\mathrm{Cys}^{34}$ is expected to be the major macromolecular site for the binding of Gd-LC7-SH since it is known to be the largest extracellular depot for carrying small molecule thiols in vivo [17, and references therein]. It should however be noted that the mechanism proposed in Figure 2 will also hold for the binding of Gd-LC7-SH to any other macromolecular thiol or immobile site such as exofacial protein thiols. In Figure $2 \mathrm{~B}$ we hypothesize a mechanism by which RRx-001 treatment will abrogate such retention of Gd-LC7-SH in the tumor microenvironment.

In a previous work we carried out a detailed study of the MRI tracer kinetics of Gd-LC6-SH and compared it against Gd-DTPA-BMA (a small molecule) and Galbumin ${ }^{\circledR}$ (a macromolecule) [18]. In that study we demonstrated that delayed (50-60 min post-injection) enhancement on MRI is insensitive to injected Gd-LC6-SH dose provided the injected dose is $0.05 \mathrm{mmole} \mathrm{Gd} / \mathrm{Kg}$ or higher (a "saturating" dose). The albumin-binding properties and MRI relaxivities of Gd-LC6-SH and Gd-LC7-SH are similar [16], and therefore in the current study we have measured tumor T1 changes $50 \mathrm{~min}$ following administration of $0.05 \mathrm{mmole} / \mathrm{Kg}$ Gd-LC7-SH. At this delayed time point any free GdLC7-SH or its low molecular weight disulfide forms will have been largely cleared from circulation and a pseudosteady-state between free and macromolecule-bound GdLC7-SH expected to exist in the tumor microenvironment [18]. We have measured $\mathrm{T} 1_{50 \text { min }}$, the longitudinal MRI relaxation time of tumor $50 \mathrm{~min}$ post-administration of $0.05 \mathrm{mmol} / \mathrm{kg} \mathrm{Gd}-\mathrm{LC} 7-\mathrm{SH}$, before and after treatment of tumor-bearing mice with RRx-001. We hypothesize that the redox modifying activity of RRx-001 can be monitored through changes in tumor $\mathrm{T}_{50 \text { min }}$ on Gd-LC7-SH-enhanced MRI. In three tumor models the tumor $\mathrm{T} 1_{50 \text { min }}$ post-drug

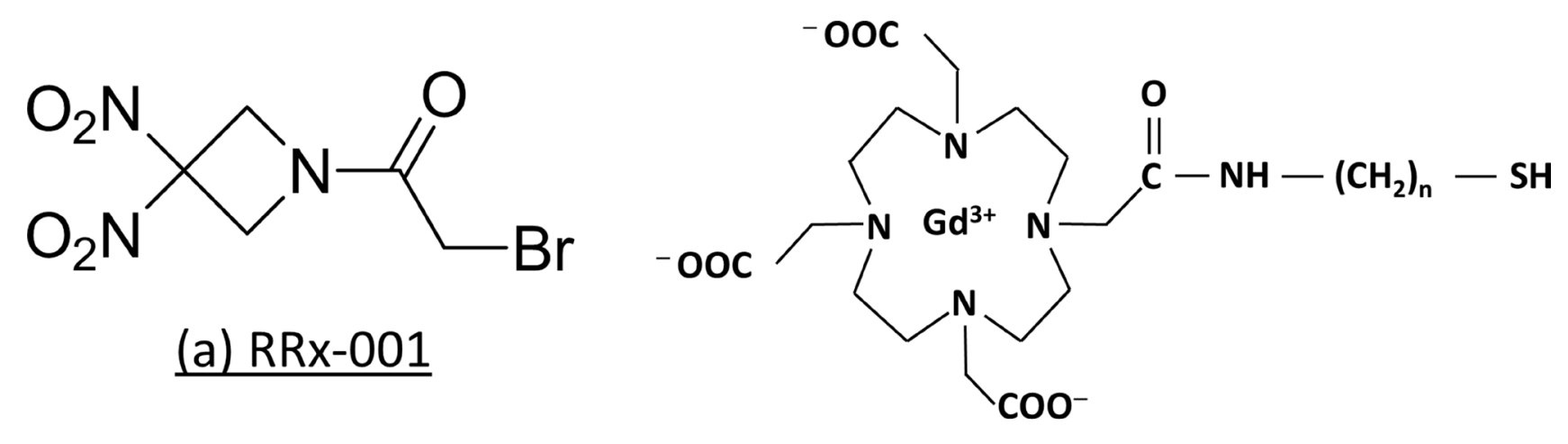

(b) Gd-LC7-SH (with $n=7$ )

Figure 1: Structures of RRx-001 and Gd-LC7-SH. 

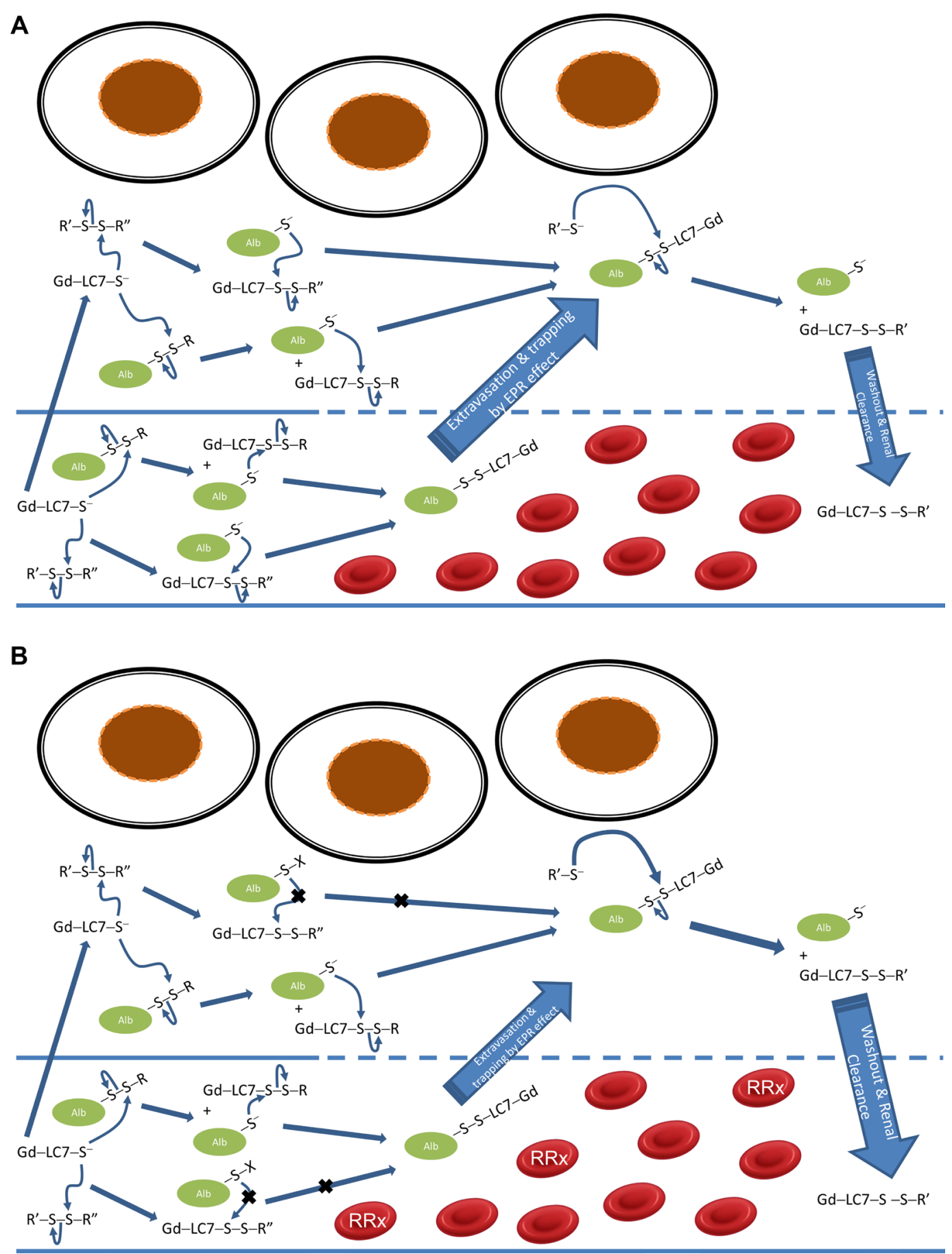

Figure 2: Mechanism of RRx-001 drug effect on decreasing retention of Gd-LC7-SH in the tumor microenvironment. The $\mathrm{pKa}$ of the thiol group in the conserved $\mathrm{Cys}^{34}$ residue on albumin is $\approx 5$, such that at physiological $\mathrm{pH}$ about two-thirds of it exists as thiolate anion (Alb-S-) while the rest is disulfide-bonded to small molecule thiols (Alb-S-S-R) [17]. For the purposes of clarity we have depicted small molecule thiols also as thiolate anions; actual reactions may involve both the thiolate and thiol forms, depending on the $\mathrm{pK}_{\mathrm{a}}$ and their relative nucleophilicity. (A) Two possible reactions by which i.v. administered Gd-LC7-SH spontaneously binds to plasma albumin at $\mathrm{Cys}^{34}$ are depicted. Late signal enhancement on MRI is primarily due to albumin-bound gadolinium trapped in the tumor interstitium by the Enhanced Permeability \& Retention (EPR) effect. Bound gadolinium can be released from the albumin by competing small molecule thiols R'-SH. (B) RRx-001 binds to the Cys ${ }^{93}$ residue on hemoglobin in a subset of RBCs (indicated by 'RRx'). Localization of RRx-001 bound RBCs to the tumor produces oxidative stress with release of ROS, RNS and free iron, which in turn lead to oxidative and nitrosative modifications of albumin-Cys ${ }^{34}$ (indicated by $-\mathrm{S}-\mathrm{X}$ where $\mathrm{X}=\mathrm{NO}, \mathrm{OH}, \mathrm{O}_{2} \mathrm{H}$ or $\mathrm{O}_{3} \mathrm{H}$ ). This decreases binding of Gd-LC7-SH to albumin-Cys ${ }^{34}$ and retention in the tumor interstitium. EPR retention of albumin-bound Gd-LC7-SH may be further decreased if there is compensatory production of small molecule thiols R'-SH by oxidatively stressed tumor cells, which can competitively release Gd-LC7-SH from the albumin resulting in accelerated washout from the tumor microenvironment. 
was longer than pre-drug tumor $\mathrm{T} 1_{50 \text { min }}$, indicative of decreased retention of Gd-LC7-SH post-treatment in the tumor. Additionally, post-drug $\mathrm{T}_{50 \text { min }}$ of CHP-100 tumors recovered to baseline values significantly faster than in PANC-1 and HT-29 tumors; this recovery was associated with an acute increase in CHP-100 tumor perfusion measured by Dynamic Contrast-Enhanced (DCE-) MRI at $1 \mathrm{~h}$ post-drug. We also investigated Blood Oxygen Level Dependent (BOLD) MRI as a potential biomarker of the NO-related vascular effects of RRx-001.

\section{RESULTS}

\section{Gd-LC7-SH MRI results}

As depicted in Figure 2A, the fraction of gadolinium that is bound to albumin (or other macromolecular target) in the tumor will experience delayed washout due to the EPR effect. This prolonged retention of Gd-LC7-SH is apparent on tumor T1 maps measured by MRI before vs. $50 \mathrm{~min}$ after administration of Gd-LC7-SH to the animal (Figure 3A, panels (ii) vs. (iii)). As hypothesized in Figure 2B, blocking of the binding of Gd-LC7-SH to albumin by RRx-001 treatment will result in faster washout of Gd-LC7-SH. This faster washout of Gd-LC7-SH is apparent as a longer post-drug tumor $\mathrm{T} 1_{50 \text { min }}$ relative to pre-drug tumor $\mathrm{T}_{50 \text { min }}$ (Figure $3 \mathrm{~A}$, panels (v) vs. (iii)). As summarized in Figure $3 \mathrm{~B}$, the $\mathrm{T} 1_{50 \text { min }}$ at $1 \mathrm{~h}$ post-treatment with RRx-001 was significantly longer than pre-treatment $\mathrm{T} 1_{50 \text { min }}$ in CHP-100 tumors $(1.57 \pm 0.05 \mathrm{~s} v s .1 .35 \pm 0.02 \mathrm{~s}$, $p=0.014)$, PANC-1 tumors $(1.04 \pm 0.05 \mathrm{~s} v s .0 .74 \pm 0.05$ $\mathrm{s}, p=0.006)$ and HT-29 tumors $(1.47 \pm 0.01 \mathrm{~s} v s .0 .78 \pm$ $0.03 \mathrm{~s}, p=7 \times 10^{-5}$ ). Tumor $\mathrm{T} 1_{50 \mathrm{~min}}$ remained significantly longer than pre-treatment $\mathrm{T} 1_{50 \text { min }}$ even $72 \mathrm{~h}$ post-drug in PANC-1 tumors $(0.90 \pm 0.02 \mathrm{~s} v s .0 .74 \pm 0.05 \mathrm{~s}, p=0.047)$ and HT-29 tumors $(1.04 \pm 0.02 \mathrm{~s} v s .0 .78 \pm 0.03 \mathrm{~s}, p=7$ $\times 10^{-4}$ ), pointing to a prolonged oxidative effect of RRx001 on the microenvironment in these tumors (Figure 3B). The $\mathrm{T} 1_{50 \text { min }}$ in CHP-100 tumors was statistically indistinguishable from pre-treatment $\mathrm{T}_{50 \text { min }}$ at $24 \mathrm{~h}$ postdrug and had recovered to baseline levels by $72 \mathrm{~h}$ postdrug, suggesting a robust anti-oxidant response to the drug in these tumors (Figure 3B).

\section{DCE-MRI results}

DCE-MRI data were collected for only the first 5 min post-second-bolus of Gd-LC7-SH, and the $\mathrm{K}^{\text {trans }}$ parameter calculated from fitting this data to the Tofts model is therefore weighted primarily toward perfusion rather than microvascular permeability [19]. Pre-treatment $\mathrm{K}^{\text {trans }}$ was similar in all three tumor models (Figure 3C). In the CHP-100 tumors, $\mathrm{K}^{\text {trans }}$ was markedly higher $1 \mathrm{~h}$ post-treatment relative to the pre-treatment value (Figure 3C, $0.14 \pm 0.01 \mathrm{~min}^{-1}$ vs. $0.06 \pm 0.01 \mathrm{~min}^{-1}$, $p=0.003$ ), indicating an acute increase of tumor perfusion in response to $\mathrm{RRx}-001$ which was not apparent at later times post-drug. No significant change in tumor $\mathrm{K}^{\text {trans }}$ relative to baseline was observed in the PANC-1 and HT29 tumors at any times post-drug (Figure 3C). Tumor $\mathrm{v}_{\mathrm{e}}$ and $\mathrm{v}_{\mathrm{p}}$ were not significantly altered, relative to baseline, by RRx-001 treatment in any of the three tumor models at any times post-drug (data not shown).

\section{BOLD MRI results}

The transverse relaxation time $\mathrm{T} 2 *$ measured by MRI is sensitive to changes in deoxyhemoglobin content arising from either local vasodilation or local changes in oxygen tension [20]. RRx-001 is known to alkylate a thiol on hemoglobin and trigger downstream effects on erythrocytes and NO production [11]. Therefore, tumor T2* was measured before, during, and after RRx-001 administration (Figure 4A). No significant acute changes in $\mathrm{T} 2 *$ relative to baseline were observed in any of the tumor models between 0-60 min following RRx-001 (Figure 4B). Tumor T2* was also measured $24 \mathrm{~h}$ and $72 \mathrm{~h}$ post-drug, though any apparent $\mathrm{T} 2 *$ changes at these two time points relative to baseline are difficult to interpret, given that field inhomogeneity contributions to $\mathrm{T}^{*}$ would have been different on Day 1 (0-60 min post-drug), Day 2 (24 h post-drug), and Day 4 (72 h post-drug). Subject to that caveat, the T2* of CHP-100 tumors was significantly lower at $72 \mathrm{~h}$ post-drug relative to baseline (Figure 4B, $15.99 \pm 0.17 \mathrm{~ms} v s .16 .89 \pm 0.16 \mathrm{~ms}$, $p<0.0001)$. Subject to the same caveat regarding differing contributions of field inhomogeneity to $\mathrm{T} 2 *$ measured during different MRI sessions, the T2* of CHP-100 tumors was significantly longer than those of PANC-1 and HT-29 tumors in the 0-60 min post-drug window (Figure 4B). This is potentially reflective of better tumor oxygenation (lower tumor deoxyhemoglobin) in CHP-100 tumors at baseline and post-drug.

\section{DISCUSSION}

Although the structure of RRx-001 may suggest that this agent binds to intratumoral thiols by covalent and irreversible alkylation leading to direct changes in the tumor redox environment, the metabolism of RRx-001 [11], characterized by a very short half-life in whole blood and by irreversible and selective binding with glutathione and the beta-Cys-93 residue on hemoglobin, suggests a more complex mechanism of action. Binding of RRx001 to hemoglobin and glutathione depletion lead to an increase in the oxidative stress of red blood cells exposed to RRx-001. While the RRx-001-GSH adduct is excreted rapidly (terminal half-life $\sim 30 \mathrm{~min}$ ), the RRx-001-bound hemoglobin adduct persists for the lifetime of the red blood cell [11-14]. Oxidatively and nitrosatively stressed erythrocytes are characterized by changes in hemoglobin oxygen affinity arising from hemoglobin conformational 
changes, highly potentiated nitrite reductase activity under hypoxic conditions [21-22], and, with very high oxidation levels, membrane scrambling manifested by externalization of phosphatidyl serine. These changes lead to aggregation of the RRx-001-bound RBCs, followed by internalization by tumor vasculature [23], leading to a release of heme, iron, and oxidized lipid products, that is, ROS and RNS, as well as changes in tumor blood flow.

In a previous study of congeners of Gd-LC7-SH, we found that the binding of Gd-LC3-SH $(n=3$ in Figure 1B) through Gd-LC7-SH ( $n=7$ in Figure 1B) to HSA is consistent with single-site binding at the conserved $\mathrm{Cys}^{34}$ residue of HSA, and that the homocysteine-inhibitable binding affinity for HSA increases in the order Gd-LC3SH through Gd-LC7-SH [16]. For this reason we used GdLC7-SH in the present study to investigate the oxidative effects of RRx-001 on tumor tissue in vivo. In all three tumor models, RRx-001 treatment resulted in longer tumor $\mathrm{T} 1_{50 \min }$ values at $1 \mathrm{~h}$ post-drug relative to pre-drug values, which is consistent with accelerated washout of Gd-LC7SH due to drug effect, as hypothesized in Figure 2. This effect was apparent even at $72 \mathrm{~h}$ post-drug in the two carcinoma models, PANC-1 and HT-29. In the CHP-100 Ewing sarcoma model, however, the tumor $\mathrm{T} 1_{50 \text { min }}$ at $24 \mathrm{~h}$ and $72 \mathrm{~h}$ post-drug was not significantly different from pre-drug values. This suggests that this tumor mounts a strong anti-oxidant response to the RRx-001 challenge, possibly stemming from the known activation of NRF2 signaling in sarcomas [24-25]. One component of an antioxidant response would be improved perfusion, and there was a marked increase in the $\mathrm{K}^{\text {trans }}$ parameter calculated from DCE-MRI of CHP-100 Ewing sarcoma xenografts at $1 \mathrm{~h}$ post-drug treatment. DCE-MRI data were collected to 5 min post-injection of a second bolus of Gd-LC7$\mathrm{SH}$, and contrast agent distribution kinetics in the early phase are thought to be dominated by perfusion rather than by microvascular permeability and leakage [19]. In contrast to the acute response observed in CHP-100 tumors, no significant change in perfusion was measured at any time points post-drug in the PANC-1 and HT-29 carcinoma xenografts. Unlike in carcinomas, the vascular network in Ewing sarcomas is formed by a combination of angiogenesis and vasculogenesis. While the development of a vascular net by angiogenesis is common with many tumor types, vasculogenesis, the process by which bone marrow-derived cells are recruited into newly developing vasculature, leads to a more mature vascular phenotype [26], potentially as a result of enhanced PDGFr signaling [27]. This more mature vasculature, together with reduced thrombospondin [28] levels that modulate the

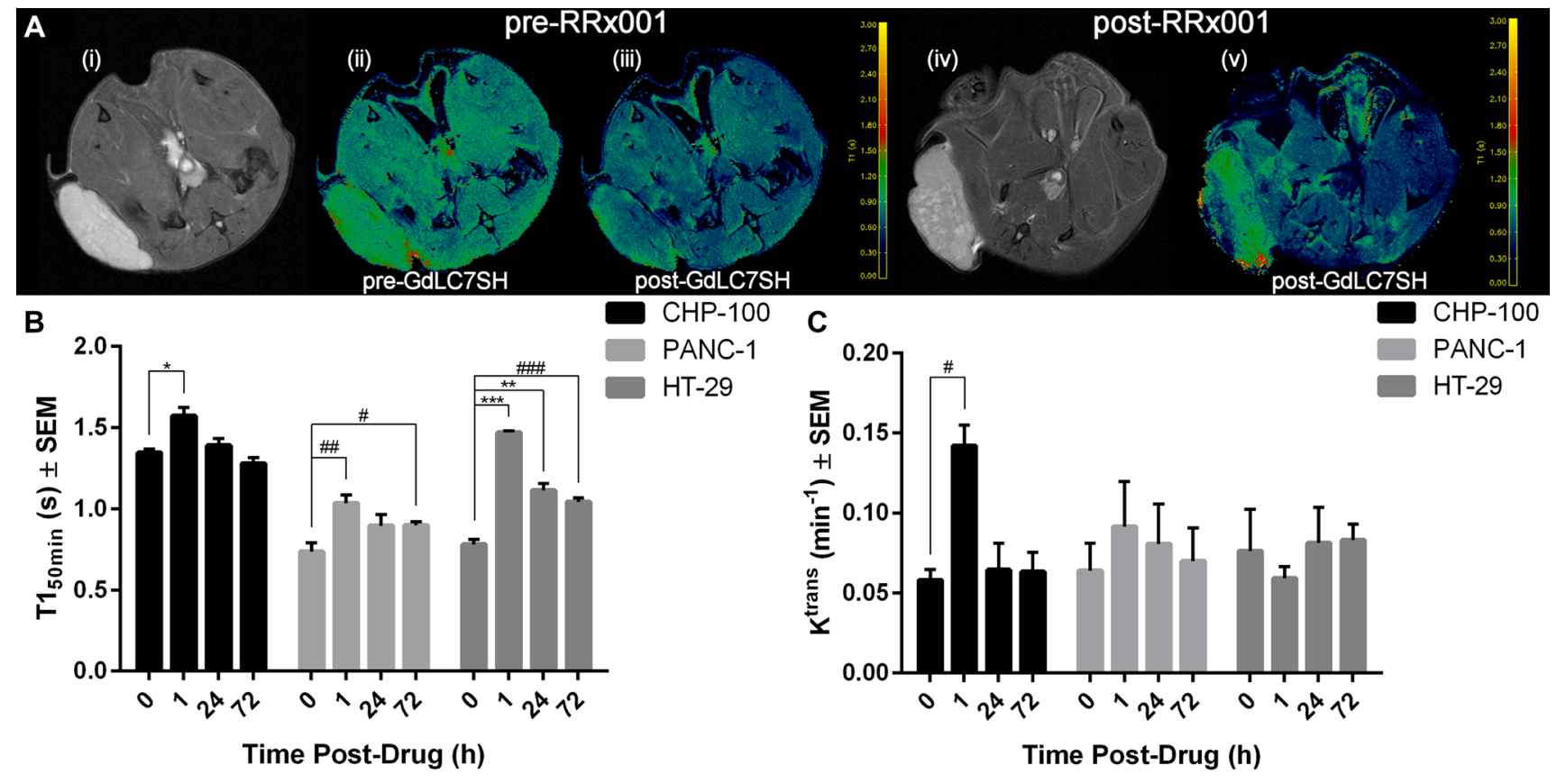

Figure 3: Gd-LC7-SH MRI of 3 tumor models. (A) Anatomic reference images and example T1 maps before and 50 min after Gd-LC7-SH of a mouse bearing a HT-29 tumor xenograft; the color scale runs from $0 \mathrm{~s}$ (dark blue) through $3 \mathrm{~s}$ (yellow). Before treatment with RRx-001 (panel (iii)) the T1 of both tumor and muscle are significantly lower post-Gd-LC7-SH relative to pre-Gd-LC7-SH (panel (ii)). $24 \mathrm{~h}$ after RRx-001 exposure the $\mathrm{T} 1_{50 \text { min }}$ of tumor is higher than expected (panel (v)), consistent with a rapid clearance of Gd-LC7-SH from the treated tumor. (B) Tumor T1 (mean \pm S.E.M., $n=4$ ) measured 50 min post-Gd-LC7-SH, before $v s$. 1-72 h after treatment with $\mathrm{RRx}-001\left(10 \mathrm{mg} / \mathrm{kg}, i . v\right.$.). In all three tumors, the $\mathrm{T} 1_{50 \text { min }}$ at $1 \mathrm{~h}$ post-treatment with $\mathrm{RRx}-001$ was significantly higher than pre-treatment $\mathrm{T}_{50 \text { min }}\left({ }^{*} p=0.014,{ }^{\#} p=0.006,{ }^{* * *} p=7 \times 10^{-5}\right)$. In HT-29 and PANC-1 tumors this effect of RRx-001 on tumor T1 ${ }_{50 \text { min }}$ was apparent even at 72 h post-drug $\left({ }^{\#} p=0.047,{ }^{* *} p=0.001,{ }^{\# \#} p=7 \times 10^{-4}\right)$. (C) $\mathrm{K}^{\text {trans }}$, a measure of tumor perfusion measured by DCE-MRI, before $v S$. after treatment with RRx-001 (10 mg/kg, i.v.). In CHP-100 tumors, tumor perfusion was significantly higher $1 \mathrm{~h}$ post-treatment with RRx-001 relative to baseline $\left({ }^{\#} p=0.003\right)$. 
physiological effects of nitric oxide through the inhibition of cGMP production [29], may result in a phenotype that is acutely responsive to the presence of nitric oxide, potentially explaining the acute changes in perfusion induced by RRx-001 in the CHP-100 tumors.

T2* of CHP-100 tumors measured in the 0-60 min post-drug time period were significantly longer than the T2* of PANC-1 and HT-29 tumors. While several factors can impact $\mathrm{T} 2 *$, longer $\mathrm{T} 2 *$ values may reflect lower levels of deoxyhemoglobin in CHP-100 tumors relative to PANC-1 and HT-29 tumors, in turn suggesting that these tumors are better perfused. We have previously investigated changes in tumor blood flow induced by RRx-001 using contrast-enhanced ultrasound [12] and immunohistochemistry (IHC) of pimonidazole [30]. Pimonidazole staining showed that, while parts of the tumor experienced an almost total shutdown of blood flow, the overall level of hypoxia within tumors was not significantly altered by RRx-001 treatment, suggesting a redistributive effect rather than outright vascular disruption [12]. This may explain why we did not see an acute change in average tumor $\mathrm{T} 2 *$ in response to RRx-001 in any of the three tumor models.

In conclusion, MRI enhanced with Gd-LC7-SH provides a non-invasive pharmacodynamic marker of the redox modulatory activity of $\mathrm{RRx}-001$ in three preclinical tumor models. DCE-MRI provides evidence of an acute increase of tumor perfusion in CHP-100 Ewing

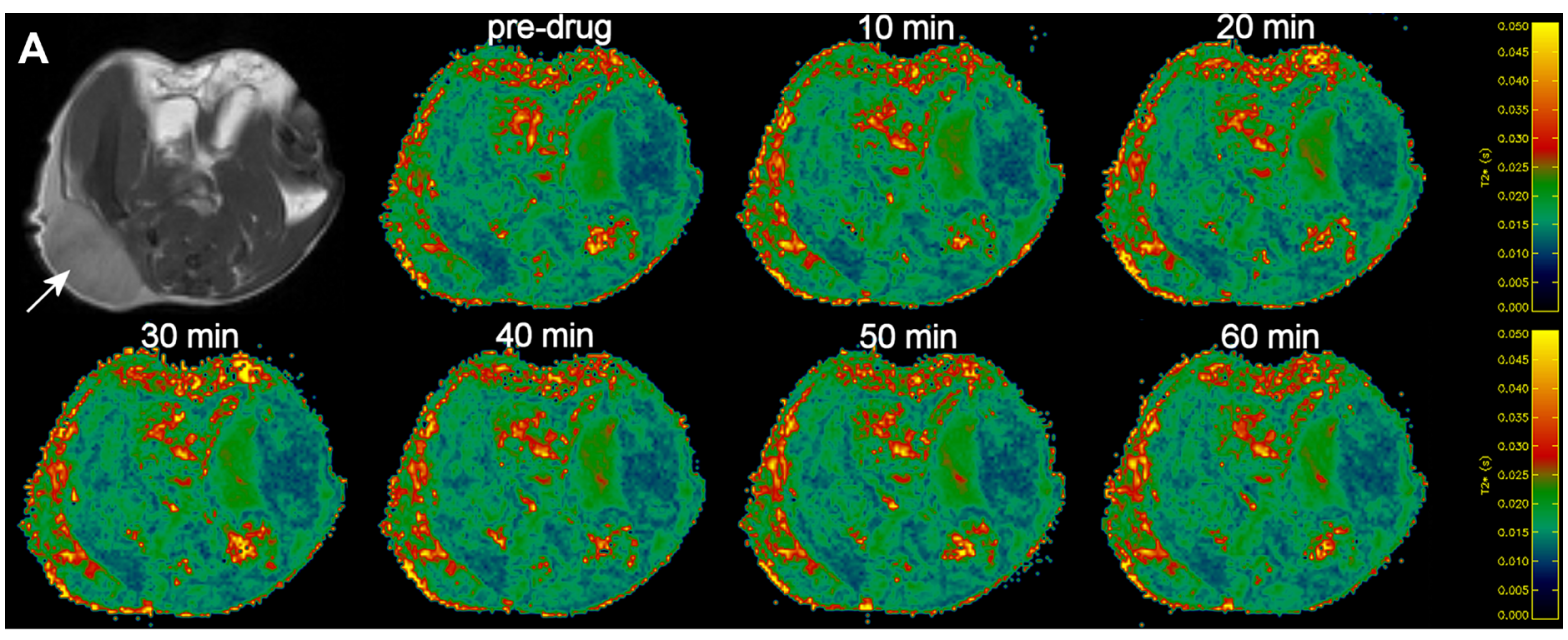

B

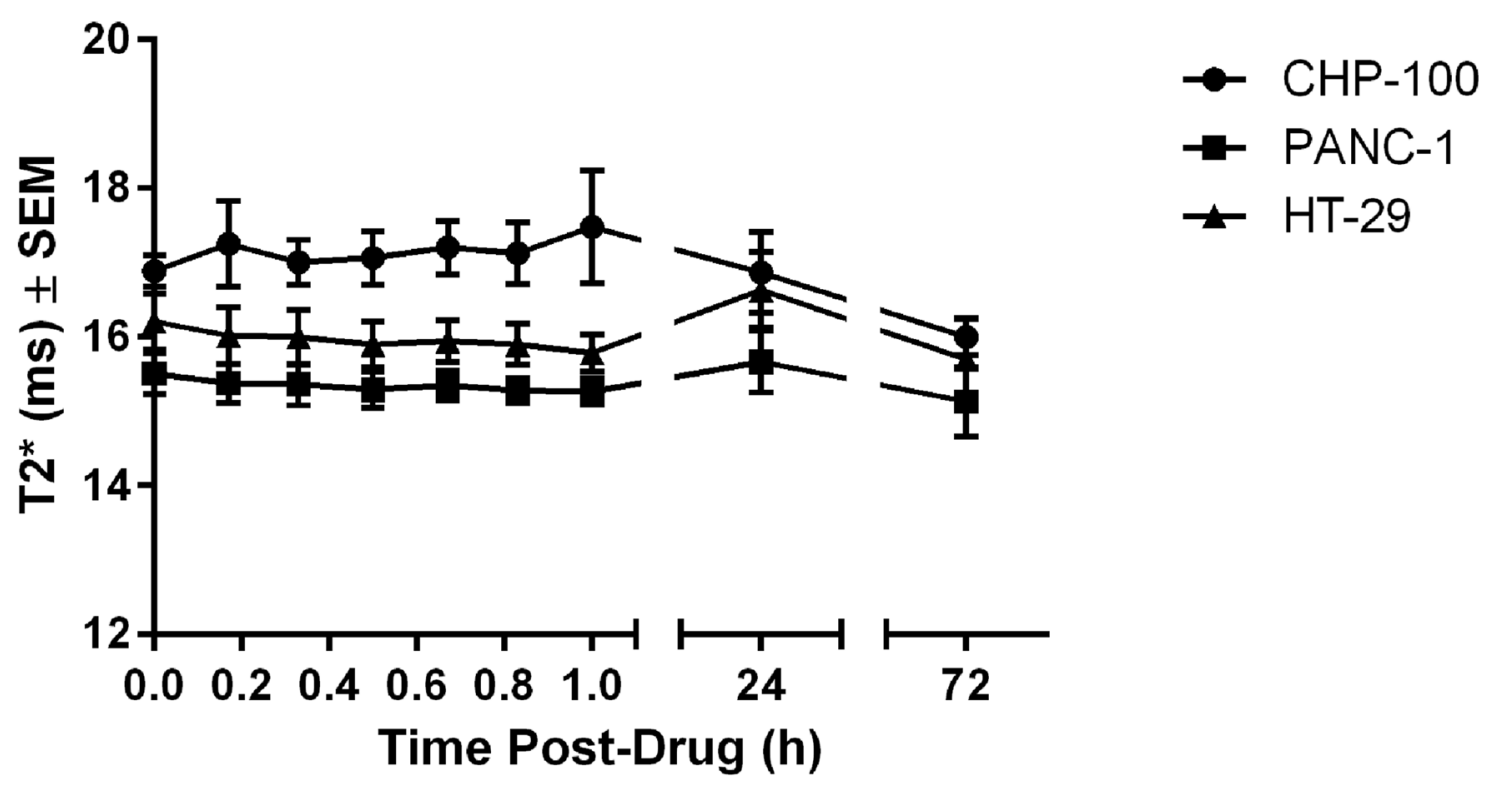

Figure 4: BOLD MRI of 3 tumor models. (A) Anatomic reference images and example T2* maps acquired in a mouse bearing a CHP-100 tumor (arrow); the color scale runs from $0 \mathrm{~ms}$ (dark blue) through $50 \mathrm{~ms}$ (yellow). (B) T2* maps were acquired before and through $60 \mathrm{~min}$ after RRx-001 treatment, and again at $24 \mathrm{~h}$ and $72 \mathrm{~h}$ post-drug. The variation of tumor T2* (mean $\pm \mathrm{S}$.E.M., $n=4$ ) before vs. after treatment with RRx-001 (10 mg/kg, i.v.). 
sarcoma tumors following RRx-001 therapy. We are exploring the addition of DCE-MRI as an investigational pharmacodynamic biomarker to ongoing clinical studies of RRx-001 (NCI Clinical Trials Identifier NCT02215512, [31]), while continuing with the development of Gd-LC7SH. Clinically, localized soft-tissue sarcomas (STS) are commonly treated with preoperative radiotherapy, and hypoxia in STS has been reported to be associated with radioresistance [32]. Our results in a pre-clinical model of Ewing sarcoma, if borne out in a wider study, offer hope that RRx-001 may be useful as a radiosensitizer for neoadjuvant radiotherapy of STS.

\section{MATERIALS AND METHODS}

\section{Mice, tumors, and drug}

All animal experiments were conducted in accordance with the guidelines of the Institutional Animal Care and Use Committee (IACUC) at the University of Arizona. CHP-100 Ewing's Sarcoma, HT-29 colorectal carcinoma, and PANC-1 pancreatic carcinoma cells were originally obtained from ATCC, and xenografts on flanks of 6-week old female Severe Combined Immunodeficient (SCID) mice were established by subcutaneous injection of $1 \times 10^{7}$ cells. 18 mice were inoculated with each tumor cell line, of which the 12 mice with the most similar mean tumor volumes were stratified into 3 equal treatment groups when the tumors were approximately 250-400 $\mathrm{mm}^{3}$ : Gd-LC7-SH MRI group $1(n=4)$, Gd-LC7-SH MRI group $2(n=4)$, and BOLD MRI group $3(n=4)$. Animals were monitored every three days for general health, body weight, and tumor volume by caliper measurement. RRx-001 was obtained from EpicentRx, Inc., [33] and prepared as a $5 \mathrm{mg} / \mathrm{mL}$ solution in saline containing dimethylacetamide $(7.5 \% \mathrm{v} / \mathrm{v})$ and polyethylene glycol $400(15 \% \mathrm{v} / \mathrm{v})$. RRx-001 solution was used within six hours of preparation and administered to mice at a dose of $10 \mathrm{mg} / \mathrm{kg}(0.05 \mathrm{~mL}$ i.v. to a $25 \mathrm{~g}$ mouse $)$ as described below. Gd-LC7-SH was synthesized as described previously [16], prepared as a $25 \mathrm{mM}$ solution in injectable saline at $\mathrm{pH} 7.4$, and administered to mice at a dose of $0.05 \mathrm{mmole} / \mathrm{kg}(0.05 \mathrm{~mL}$ i.v. to a $25 \mathrm{~g}$ mouse $)$ as described below.

\section{Magnetic resonance imaging}

Mice were imaged on a 7 Tesla Bruker Biospec ${ }^{\circledR}$ small animal MRI scanner. Mice were anesthetized using isoflurane $\left(1.5-2.5 \%\right.$ in $\left.\mathrm{O}_{2}, 1 \mathrm{~L} / \mathrm{min}\right)$ and cannulated at the tail vein with an i.v. line of $\sim 25 \mu \mathrm{L}$ dead volume for administration of Gd-LC7-SH or RRx-001. A pressure transducer pad for monitoring respiration was placed under the anesthetized animal, and the mouse was gently secured in a plastic holder. The animal was loaded into a $25-\mathrm{mm}$-ID small animal imaging Litz coil (Doty Scientific, Columbia,
SC) and the entire assembly was centered inside the MRI magnet. Animal body temperature was maintained using a forced warm air system and monitored during imaging using a fluoroptic rectal temperature probe (SA Instruments, Stony Brook, NY). Isoflurane was adjusted manually to maintain animal respiration rate largely in the $35-45$ breaths/min range during scanning. Scout images were acquired for planning axial slices to be imaged through the tumor, followed by acquisition of $\mathrm{T} 2$-weighted anatomic reference images in the final slice geometry. For computing longitudinal relaxation time (T1) maps, eight gradient-echo (GRE) images were acquired using the following parameters at a scan time of 80 seconds per image: repetition time $(\mathrm{TR})=78$ milliseconds, echo time $(\mathrm{TE})=3.5$ milliseconds, matrix $=256 \times 256$, field of view $(\mathrm{FOV})=3 \times 3 \mathrm{~cm}$, slice thickness $=2 \mathrm{~mm}$, number of averages (NA) $=4$, and flip angles $(\mathrm{FA})=5^{\circ}, 15^{\circ}$, $25^{\circ}, \ldots 75^{\circ}$ (8 flip angles). DCE-MRI was performed by GRE imaging with the following parameters: $\mathrm{TR}=78$ milliseconds, $\mathrm{TE}=3.5$ milliseconds, $\mathrm{FA}=75^{\circ}, \mathrm{NA}=1$, number of repetitions $=15$, scan time $=5 \mathrm{~min}$. BOLD MRI was performed by acquiring multi-echo gradientecho (mGRE) images with the following parameters: $\mathrm{TR}=300 \mathrm{~ms}, \mathrm{TE}=4,12,20, \ldots 60 \mathrm{~ms}$ ( 8 echoes $)$, $\mathrm{FA}=25^{\circ}, \mathrm{NA}=8$, matrix $=128 \times 128, \mathrm{FOV}=3 \times 3 \mathrm{~cm}$, slice thickness $=2 \mathrm{~mm}$.

\section{Gd-LC7-SH MRI, group 1}

Mice in this group were imaged before treatment $(0 \mathrm{~h})$ and $24 \mathrm{~h}$ post-treatment as in Figure 5A. Mice were prepared for MRI as described above and T1 maps of the tumor were acquired $50 \mathrm{~min}$ post-injection of $0.05 \mathrm{mmol} / \mathrm{kg}$ Gd-LC7-SH (i.v.) in untreated mice. At this point a second bolus of $0.05 \mathrm{mmol} / \mathrm{kg}$ Gd-LC7-SH with $0.1 \mathrm{~mL}$ saline flush was administered and DCE-MRI was performed. At the end of scanning, the mouse was kept anesthetized outside the magnet for approximately $40 \mathrm{~min}$, with the i.v. line still in place, at which time RRx-001 was injected. This delay was to allow the previously injected Gd-LC7$\mathrm{SH}$ to either form mixed disulfides with targets in vivo or be cleared from the animal, thereby avoiding direct reaction between RRx-001 and Gd-LC7-SH. Mice in this group were re-imaged $24 \mathrm{~h}$ post-administration of RRx-001, after which they were sacrificed by cervical dislocation under anesthesia (4\% isoflurane) and the tumors harvested.

\section{Gd-LC7-SH MRI, group 2}

Mice in this group were imaged $1 \mathrm{~h}$ and $72 \mathrm{~h}$ posttreatment, as in Figure 5B. Mice were prepared for MRI as described above and administered RRx-001, followed by a $0.1 \mathrm{~mL}$ saline flush. The purpose of the saline flush was to clear the i.v. line of residual RRx-001 and to prevent direct reaction with Gd-LC7-SH that was administered $10 \mathrm{~min}$ later $(0.05 \mathrm{mmol} / \mathrm{kg})$. Unreacted RRx-001 has a very short 
half-life in blood, on the order of seconds [11, 34], and so the 10 min delay was considered sufficient to prevent direct reaction between RRx-001 and Gd-LC7-SH in vivo. Mice were then transferred into the magnet, and T1 maps of the tumor were acquired 50 min post-injection of GdLC7-SH (1 h post-drug). At this point, a second bolus of $0.05 \mathrm{mmol} / \mathrm{kg}$ Gd-LC7-SH with a $0.1 \mathrm{~mL}$ saline flush was administered and DCE-MRI was performed. Mice in this group were re-imaged $72 \mathrm{~h}$ post-administration of RRx-001, after which they were sacrificed by cervical dislocation under anesthesia (4\% isoflurane) and the tumors harvested.

\section{BOLD MRI, group 3}

Mice in this group were imaged before, during, and through to $60 \mathrm{~min}$ after treatment, $24 \mathrm{~h}$ post-treatment, and $72 \mathrm{~h}$ post-treatment, as in Figure 5C. Mice were prepared for MRI as described above, and two mGRE image sets were acquired before treatment. Then RRx-001 was administered in-magnet via the i.v. line, and additional mGRE datasets were acquired through to $1 \mathrm{~h}$ post-drug. Mice in this group were re-imaged at $24 \mathrm{~h}$ and $72 \mathrm{~h}$ post-administration of RRx-001, after which they were sacrificed by cervical dislocation under anesthesia (4\% isoflurane) and the tumors harvested.

\section{MRI data analysis}

The signal intensities in the $8 \mathrm{GRE}$ images acquired with 8 flip angles were fitted by non-linear regression on a pixel-by-pixel basis to the gradient-echo signal equation to compute T1 maps. T2* maps were calculated by linear regression of the natural logarithm of the pixel-by-pixel signal intensities in the mGRE images $v s$. TE. DCE-MRI was performed following a second bolus of Gd-LC7-

A

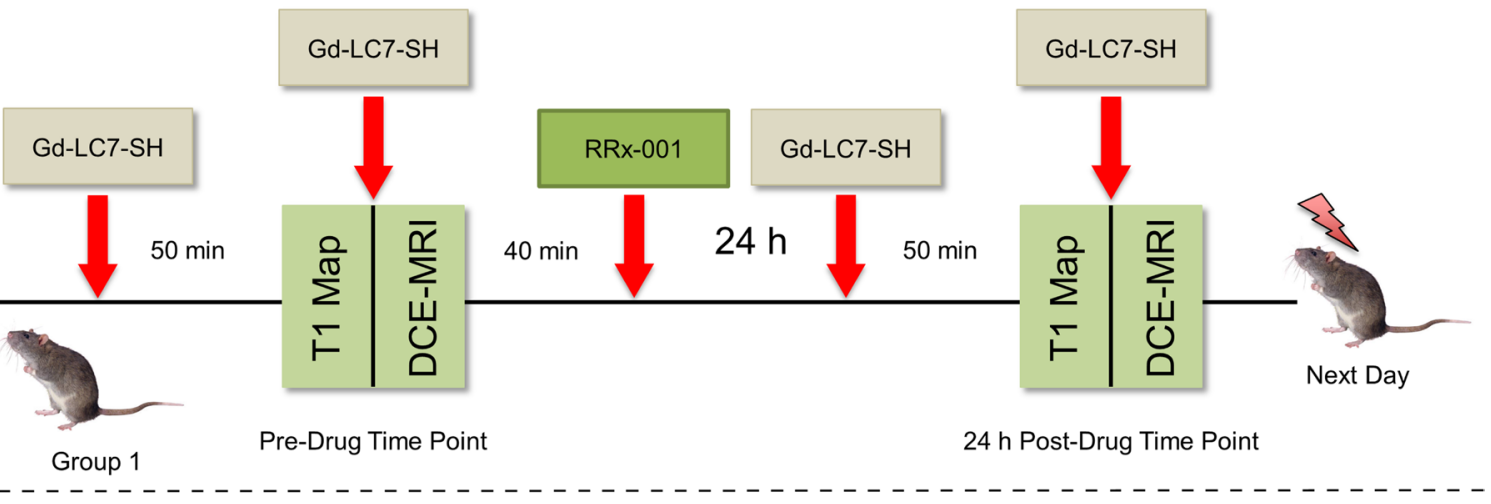

B

B

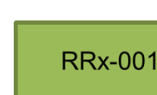

Gd-LC7-SH

Gd-LC7-SH
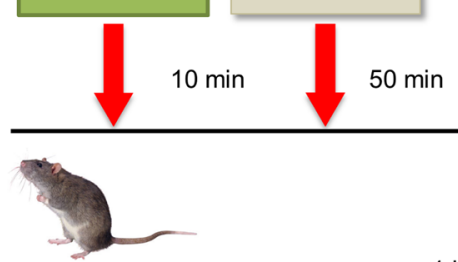

Group 2
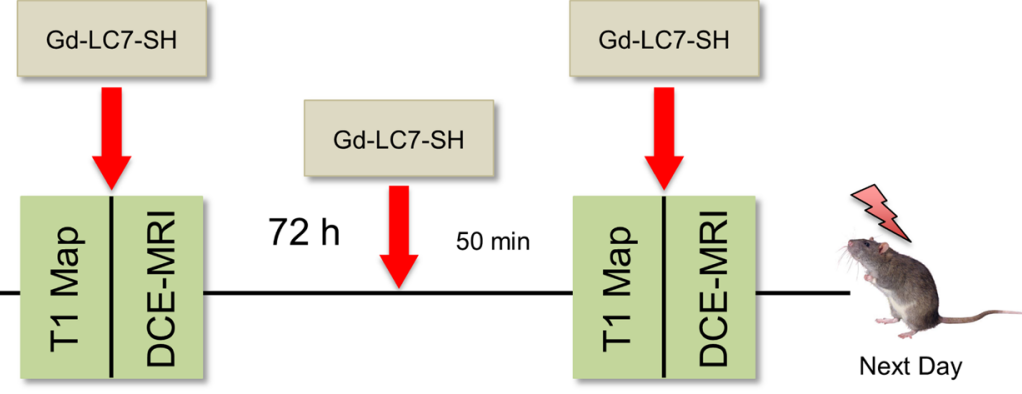

$1 \mathrm{~h}$ Post-Drug Time Point

72 h Post-Drug Time Point

c
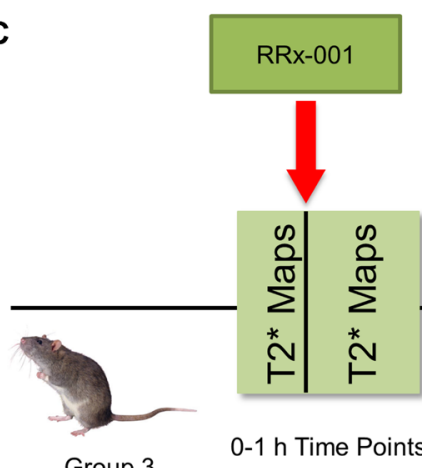

1h Post-Drug Time Point

Group 3

-1 h Time Points

$24 \mathrm{~h}$
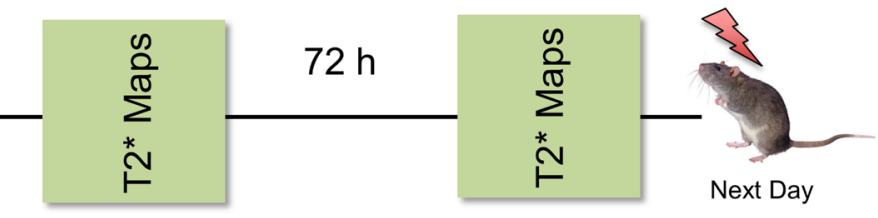

24 h Post-Drug Time Point

72 h Post-Drug Time Point

Figure 5: Designs of the Gd-LC7-SH MRI, DCE-MRI, and BOLD MRI experiments. 
$\mathrm{SH}$ administered $\approx 60 \mathrm{~min}$ after the first bolus. We have previously reported a method for quantitative analysis of dual-bolus DCE-MRI images in which the residual timevarying signal intensity from the first bolus was estimated by fitting a biexponential washout function and subtracted from the time-varying signal intensity following the second bolus [35]. Based on the in vivo behavior of a related molecule, Gd-LC6-SH [18, 36], we have assumed that at $\approx 60 \mathrm{~min}$ post-injection of Gd-LC7-SH the signal enhancement from the first bolus is essentially timeinvariant during the $5 \mathrm{~min}$ DCE-MRI measurement following the second bolus. DCE-MRI signal intensities were therefore corrected by simply subtracting the presecond-bolus signal intensity, rather than a time-varying washout function, from each time point. Pixel-by-pixel pharmacokinetic analysis of this corrected DCE-MRI data was performed using a modified Tofts model [19]. Three physiologically relevant model parameters were fitted for each pixel, the volume transfer constant ( $\left.\mathrm{K}^{\text {trans }}\right)$, volume fraction of the extravascular extracellular space $\left(\mathrm{V}_{\mathrm{e}}\right)$, and plasma volume fraction $\left(\mathrm{v}_{\mathrm{p}}\right)$ [37].

\section{CONFLICTS OF INTEREST}

JS and BO are employees of EpicentRx.

\section{FINANCIAL SUPPORT}

This work was sponsored by EpicentRx and also partly supported by grants R01-CA118359 and P30CA023074 (Imaging, Synthetic Chemistry \& Mouse Cores) from the National Institutes of Health.

\section{REFERENCES}

1. Scicinski J, Oronsky B, Ning S, Fanger GR, Knox SJ, Bednarski M. Discovery and Development of RRx-001, a Novel Nitric Oxide and ROS Mediated Epigenetic Modulator. In: Bonavida B, Ed. Nitric Oxide and Cancer: Pathogenesis and Therapy, Springer. 2015: 259-277.

2. Scicinski J, Oronsky B, Ning S, Knox S, Peehl D, Kim MM, Langecker P, Fanger G. NO to cancer: The complex and multifaceted role of nitric oxide and the epigenetic nitric oxide donor, RRx-001. Redox Biology. 2015; 6:1-8.

3. Zhao H, Ning S, Scicinski J, Oronsky B, Knox S, Peehl DM. Epigenetic effects of RRx-001: a possible unifying mechanism of anticancer activity. Oncotarget. 2015; 6:43172-43181. https://doi.org/10.18632/oncotarget.6526.

4. Reid T, Oronsky B, Scicinski J, Scribner CL, Knox SJ, Ning S, Peehl DM, Korn R, Stirn M, Carter CA, Oronsky A, Taylor MJ, Fitch WL, et al. Safety and activity of RRx-001 in patients with advanced cancer: a first-in-human, openlabel, dose-escalation phase 1 study. The Lancet Oncology. 2015; 16:1133-1142.
5. Reid T, Dad S, Korn R, Oronsky B, Knox S, Scicinski J. Two Case Reports of Resensitization to Previous Chemotherapy with the Novel Hypoxia-Activated Hypomethylating Anticancer Agent RRx-001 in Metastatic Colorectal Cancer Patients. Case Rep Oncol. 2014; 7:79-85.

6. Oronsky BT, Oronsky AL, Lybeck M, Oronsky NC, Scicinski JJ, Carter C, Day RM, Rodriguez Orengo JF, Rodriguez-Torres M, Fanger GR, Reid TR. Episensitization: Defying Time's Arrow. Frontiers Oncol. 2015; 5:134. https://doi.org/10.3389/fonc.2015.00134.

7. Oronsky B, Oronsky N, Scicinski J, Fanger G, Lybeck M, Reid T. Rewriting the Epigenetic Code for Tumor Resensitization: A Review. Translat Oncol. 2014; 7:626-631.

8. Oronsky B, Oronsky N, Knox S, Fanger G, Scicinski J. Episensitization: therapeutic tumor resensitization by epigenetic agents: a review and reassessment. Anticancer Agents Med Chem. 2014; 14:1121-1127.

9. Oronsky BT, Oronsky NC, Fanger GR, Oronsky A, Lybeck MMC, Lybeck HE, Caroen SZ, Parker CW, Scicinski J. A Review of Two Promising Radiosensitizers in Brain Metastases: RRx-001 and 2-Deoxyglucose. J Cancer Sci Ther. 2015; 7:137-141.

10. Carter CA, Degesys A, Oronsky B, Scicinski J. Flushing Out Carcinoid Syndrome: Beneficial Effect of the Anticancer Epigenetic Agent RRx-001 in a Patient with a Treatment-Refractory Neuroendocrine Tumor. Case Rep Oncol. 2015; 8:461-465.

11. Scicinski J, Oronsky B, Taylor M, Luo G, Musick T, Marini J, Adams CM, Fitch WL. Preclinical Evaluation of the Metabolism and Disposition of RRx-001, a Novel Investigative Anticancer Agent. Drug Metab. Disp. 2012; 40:1810-1816.

12. Ning S, Bednarski M, Oronsky B, Scicinski J, Saul G, Knox SJ. Dinitroazetidines Are a Novel Class of Anticancer Agents and Hypoxia-Activated Radiation Sensitizers Developed from Highly Energetic Materials. Cancer Res. 2012; 72:2600-2608.

13. Ning S, Sekar T, Scicinski J, Oronsky B, Peehl D, Knox S, Paulmurugan R. Nrf2 activity as a potential biomarker for the pan-epigenetic anticancer agent, RRx-001. Oncotarget. 2015; 6:21547-21556. https://doi.org/10.18632/oncotarget.4249.

14. Fens MH, Larkin SK, Morris CR, Fitch B, Scicinski J, Oronsky B, Kuypers FA. NO or No NO, Increased Reduction of Nitrite to Nitric Oxide by Modified Red Blood Cells. Blood. 2011; 118:2125.

15. Paulmurugan R, Oronsky B, Brouse CF, Reid T, Knox S, Scicinski J. Real Time Dynamic Imaging and Current Targeted Therapies in the War on Cancer: A New Paradigm. Theranostics. 2013; 3:437-447.

16. Jagadish B, Guntle GP, Zhao D, Gokhale V, Ozumerzifon TJ, Ahad AM, Mash EA, Raghunand N. Redox-active Magnetic Resonance Imaging Contrast Agents: Studies with Thiolbearing 1,4,7,10-Tetraazacyclododecane-1,4,7,10-tetracetic Acid Derivatives. J Med Chem. 2012; 55:10378-10386.

17. Sengupta S, Chen H, Togawa T, DiBello PM, Majors AK, Budy B, Ketterer ME, Jacobsen DW. Albumin thiolate 
anion is an intermediate in the formation of albumin-S-Shomocysteine. J Biol Chem. 2001; 276:30111-30117.

18. Guntle GP, Jagadish B, Mash EA, Powis G, Dorr RT, Raghunand N. Tumor xenograft response to redox-active therapies assessed by Magnetic Resonance Imaging using a thiol-bearing DOTA complex of gadolinium. Translat Onco. 2012; 5:190-199.

19. Tofts PS. Modeling tracer kinetics in dynamic Gd-DTPA MR imaging. J Magn Reson Imaging. 1997; 7:91-101.

20. Ogawa S, Lee TM, Barrere B. The sensitivity of magnetic resonance image signals of a rat brain to changes in the cerebral venous blood oxygenation. Magn Reson Med. 1993; 29:205-210.

21. Fens MH, Larkin SK, Oronsky B, Scicinski J, Morris CR, Kuypers FA. The capacity of red blood cells to reduce nitrite determines nitric oxide generation under hypoxic conditions. PLoS One. 2014; 9:e101626.

22. Brouse C, Ortiz D, Su Y, Oronsky B, Scicinski J, Cabrales P. Impact of hemoglobin nitrite to nitric oxide reductase on blood transfusion for resuscitation from hemorrhagic shock. Asian J Transfus Sci. 2015; 9:55-60.

23. Fens $\mathrm{MH}$, van Wijk R, Andringa G, van Rooijen KL, Dijstelbloem HM, Rasmussen JT, de Vooght KM, Schiffelers RM, Gaillard CA, van Solinge WW. A role for activated endothelial cells in red blood cell clearance: implications for vasopathology. Haematologica. 2012; 97:500-508.

24. Je EM, An CH, Yoo NJ, Lee SH. Mutational and expressional analyses of NRF2 and KEAP1 in sarcomas. Tumori. 2012; 98:510-515.

25. Zhuo R, Kosak KM, Sankar S, Wiles ET, Sun Y, Zhang J, Ayello J, Prestwich GD, Shami PJ, Cairo MS, Lessnick SL, Luo W. Targeting glutathione S-transferase M4 in Ewing sarcoma. Front Pediatr. 2014; 2:83. https://doi.org/10.3389/ fped.2014.00083.

26. Stewart KS, Kleinerman ES. Tumor Vessel Development and Expansion in Ewing's Sarcoma: A Review of the Vasculogenesis Process and Clinical Trials with VascularTargeting Agents. Sarcoma. 2011; 2011:165837. https://doi. org/10.1155/2011/165837

27. Frischer JS, Huang J, Serur A, Kadenhe-Chiweshe A, McCrudden KW, O’Toole K, Holash J, Yancopoulos GD, Yamashiro DJ, Kandel JJ. Effects of potent VEGF blockade on experimental Wilms tumor and its persisting vasculature. Int J Oncol. 2004; 25:549-553.
28. DuBois SG, Marina N, Glade-Bender J. Angiogenesis and vascular targeting in Ewing sarcoma. Cancer. 2010; 116: 749-757.

29. Isenberg JS, Shiva S, Gladwin M. Thrombospondin-1-CD47 blockade and exogenous nitrite enhance ischemic tissue survival, blood flow and angiogenesis via coupled NOcGMP pathway activation. Nitric Oxide. 2009; 21:52-62.

30. Scicinski J, Oronsky B, Ning S, Minchinton A, Knox S. RRx-001 modulates intratumor blood flow in SCCVII and U87 tumors. Cancer Research. 2012; 72:4371. Proceedings: AACR 103rd Annual Meeting 2012- Mar 31-Apr 4, 2012; Chicago, IL.

31. Kim MM, Parmar H, Cao Y, Knox SJ, Oronsky B, Scicinski J, Lawrence TS, Lao CD. Concurrent Whole Brain Radiotherapy and RRx-001 for Melanoma Brain Metastases. Neuro-Oncology. 2016; 18:455-456.

32. Lewin J, Khamly KK, Young RJ, Mitchell C, Hicks RJ, Toner GC, Ngan NYK, Chander S, Powell GJ, Herschtal A, Te Marvelde L, Desai J, Choong PFM, et al. A phase $\mathrm{Ib} / \mathrm{II}$ translational study of sunitinib with neoadjuvant radiotherapy in soft-tissue sarcoma. British J Cancer. 2014; 111:2254-2261.

33. Straessler NA, Lesley MW, Cannizzo LF. Development of a Safe and Efficient Two-Step Synthesis for Preparing 1-Bromoacetyl-3, 3-dinitroazetidine, a Novel Clinical Anticancer Candidate. Org Process Res Dev. 2012; 16: 512-517.

34. Scicinski J, Oronsky B, Cooper V, Taylor M, Alexander M, Hadar R, Cosford R, Fleischmann T, Fitch WL. Development of methods for the bioanalysis of RRx-001 and metabolites. Bioanalysis. 2014; 6:947-956.

35. Raghunand N, Howison C, Sherry AD, Zhang S, Gillies RJ. Renal and Systemic pH Imaging by Contrast-Enhanced MRI. Magn Reson Med. 2003; 49:249-257.

36. Landowski TH, Guntle GP, Zhao D, Jagadish B, Mash EA, Dorr RT, Raghunand N. Magnetic Resonance Imaging identifies differential response to pro-oxidant chemotherapy in a xenograft model. Translat Oncol. 2016; 9:228-235.

37. Rajaraman S, Rodriguez JJ, Graff C, Altbach MI, Dragovich T, Sirlin CB, Korn RL, Raghunand N. Automated registration of sequential breath-hold dynamic contrastenhanced MR images: a comparison of three techniques. Magn Reson Imaging. 2011; 29:668-682. 